viral infection. (Novotny E, Renfroe B, Yardi N, et al. Randomized trial of adjunctive topiramate therapy in infants with refractory partial seizures. Neurology March 2, 2010;74:714-720). (Reprints: Dr Edward Novotny, Seattle Children's Hospital, 4800 Sand Point Way NE, Neurology B-555-2, Seattle, WA 98105. E-mail: ejn4@u.washington.edu).

COMMENT. In this AED study employing video EEG, topiramate is ineffective as adjunctive therapy for refractory partial-onset seizures in infants aged 1 month to 2 years. In children older than 2 years, topiramate is effective in controlling refractory seizures of multiple types and is well tolerated in doses ranging from 1 to $24 \mathrm{mg} / \mathrm{kg} / \mathrm{d}$. (Ritter FJ et al. Ann Neurol 2003;54(suppl 7):E2. Abstract).

In an editorial (Neurology 2010;74:708-709), Thio LL and Dodson WE comment that results of AED trials in adults and children cannot be extrapolated to infants with severe epilepsy. Infants with milder epilepsies than those in the Novotny trial may respond. Topiramate may be effective in new-onset epilepsy in infants under 2 years of age. Further Class I AED trials in infants should be encouraged.

\title{
LEVETIRACETAM ADD-ON THERAPY FOR ROLANDIC AND OTHER BENIGN IDIOPATHIC FOCAL EPILEPSIES
}

Effectiveness of levetiracetam (LEV) in treatment of typical benign rolandic epilepsy and variants of benign idiopathic focal epilepsies was studied in 32 children (mean age 10.6 years, range 4-14) by researchers at Epilepsy Centre for Children and Young People, Vogtareuth, Germany. Patients with a reduction in seizure frequency $>50 \%$ and/or reduction in benign idiopathic focal epileptiform discharges (BIFEDC) $>90 \% 3$ months after starting LEV therapy were defined as responders. The average dose of LEV was $39 \mathrm{mg} / \mathrm{kg} / \mathrm{d}$, and monotherapy was used in $31.3 \%$ of patients. Twenty $(62.5 \%)$ of 32 patients benefited: 12 of 24 had a $>50 \%$ reduction in seizure frequency, 2 of $24(8.3 \%)$ were completely seizure free, 18 of $32(56.3 \%)$ had a $>90 \%$ reduction in BIFEDC (including continuous spikes and waves during sleep), 6 of 32 (18.8\%) had an EEG completely free of epileptiform discharges, and 17 of $32(53.1 \%)$ showed improvement in cognition and/or language functions and/or behavior. (von Stulpnagel C, Kluger G, Leiz S, Holthausen H. Levetiracetam as add-on therapy in different subgroups of "benign" idiopathic focal epilspsies in childhood. Epilepsy Behav Feb 2010;17:193198). (Respond: Dr C von Stulpnagel. E-mail: celinal @ gmx.de).

COMMENT. The arguments opposed and general reluctance to treat the EEG abnormality in children with cognitive and behavioral disorders associated with subclinical rolandic epilepsy and atypical variants are gradually being eroded by the above and other reports. Several studies have shown that up to $50 \%$ of children with benign idiopathic focal epileptiform discharges without clinical seizures may have cognitive deficits and/or behavioral problems such as ADHD, related in part to the abnormal EEG. (Deonna T. Epileptic Disord 2000;2(Suppl 1):S59-61); Nicolai J et al. Epilepsy Behav 2006;8:56-70; Yung AW et al. Pediatr Neurol 2000;23:391-395; Schubert R. Pediatr Neurol 2005;32:1-10). 
In a prospective trial of levetiracetam, up to $40 \mathrm{mg} / \mathrm{kg} / \mathrm{d}$, in 6 children (mean age 9.8 years) with subclinical spikes associated with attention and learning difficulties, 4 children showed statistically significant improvements in Wide Range Assessment of Memory and Learning after 10 weeks. (Mintz M et al. J Child Neurol 2009;24:807-815). Cognitive improvement was associated with concomitant EEG spike suppression.

Epileptiform discharges, especially centro-temporal spikes, are recorded in $25 \%$ of sleep deprived EEGs obtained in children referred with ADHD and without clinical seizures. (Millichap, John J; Stack, Cynthia, et al. personal communication). EEGs were indicated because of episodic inattention and transient lack of awareness.

\section{ATTENTION DEFICIT AND AUTISTIC DISORDERS}

\section{ADHD OUTCOME IN COMMUNITY-BASED SETTINGS}

A total of 158 community physicians from 47 separate practices in Cincinnati, Ohio, participated in an ADHD Collaborative study designed to improve physician adherence to evidence-based AAP/ADHD treatment guidelines. Medical records of 785 children aged between 7 and 11 years were reviewed initially and every 3 months for 1 year to determine treatment outcome. Following treatment with medication alone, parentand teacher-rated ADHD symptoms showed large improvements, but functional impairment was not significantly improved. Improvement of ADHD symptoms occurred mainly in the first 3 months of medication treatment and then remained improved and stable. The degree of improvement achieved in these community settings was comparable to that reported in the Multimodal MTA Cooperative Group, medication-only study phase. Community-based physicians can achieve improvement in ADHD symptoms, similar to university-based clinical trials, Symptom improvements are not associated with functional gains in academic performance and social and family relationships. An effective treatment program must be multimodal and include, in addition to medication, collaboration with educational and psychological services. (Epstein JN, Langberg JM, Lichtenstein PK, et al. Attention-deficit/hyperactivity disorder outcomes for children treated in community-based pediatric settings. Arch Pediatr Adolesc Med Feb 2010;164(2):160-165). (Respond: Jeffery N Epstein PhD, Center for ADHD, Cincinnati Children's Hospital Medical Center, Mail Location 10006, Cincinnati, OH 45229. Email: jeff.epstein@cchmc.org).

COMMENT. Symptom improvements without significant functional gains in academic performance and social behavior may be expected in children with ADHD treated with medication alone in community-based settings. Educational, social and behavioral therapy are required to supplement medication for optimal management of ADHD.

The Multimodal Treatment Study of ADHD (MTA) was organized by the National Institute of Mental Health and collaborators to compare long-term effectiveness of various treatment strategies, 1994-1998. Patients were assigned to one of four groups: (1) medication alone, (2) combined medication/behavior modification, (3) behavior modification alone, and (4) routine community care. The medication alone group showed persisting superiority over behavior modification and community care for ADHD and 